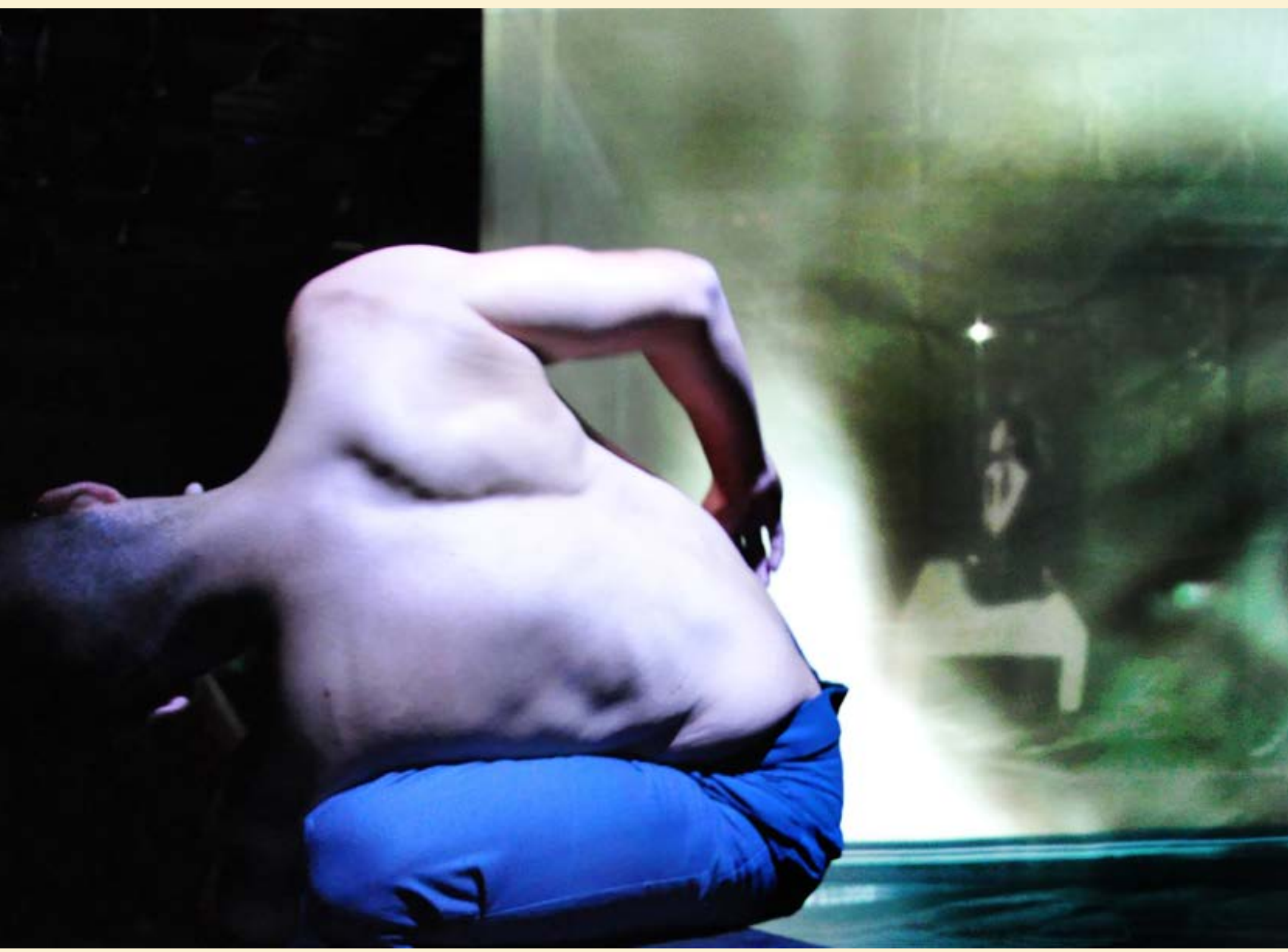

Imagen 1. EVD58' (Yaolxochitl Rodríguez Salazar, octubre 2013). Danza UNAM, Ciudad de México. 


\section{Reconfiguración del cuerpo en la danza mediada por redes telemáticas ${ }^{1}$}

Reconfiguration of the body in dance mediated by telematic networks // Reconfiguração do corpo na dança mediada por redes telemáticas

Rebeca Sánchez Aguilar²

Facultad de Artes y Diseño, UNAM, México

rebeca.sanchez.aguilar@gmail.com

Revista Corpo-grafías: Estudios críticos de y desde los cuerpos / Volumen 7 - Número 7 / Enero - diciembre 2020 / ISSN impreso 2390-0288, ISSN digital 2590-9398 / Bogotá, D.C., Colombia / 248-255

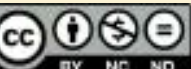

Fecha de recepción: 12 de febrero de 2019

Fecha de aceptación: 25 de julio de 2019

DOI: https://doi.org/ 10.14483/25909398.15522

Cómo citar este artículo: Sánchez Aguilar, R. (2020, enero-diciembre). Reconfiguración del cuerpo en la danza mediada por redes telemáticas. Revista Corpo-grafías: Estudios críticos de y desde los cuerpos, 7(7), pp. 248-255 / ISSN 2390-0288.

\footnotetext{
$1 \quad$ Articulo de reflexión Investigación: El presente artículo es un fragmento de la investigación de nombre La materialidad del cuerpo en la danza mediada por sistemas de redes, efectuada durante mis estudios del Doctorado en Artes Visuales, del programa de Posgrado en Artes y Diseño de la Universidad Autónoma de México.

2 Artista e investigadora interdisciplinaria que trabaja con las artes performáticas, la danza, los nuevos medios y las artes visuales en vínculo con recursos tecnológicos y la telemática. Tiene el título de European Media Master of Arts: Interactive Multimedia, de Utrecht School of Arts, Holanda. Master in Performing Arts por DasArts - Amsterdam, Holanda. Actualmente cursa el Doctorado en Artes Visuales en la Facultad de Artes y Diseño, UNAM.
} 


\section{Resumen}

Al cuerpo lo entiendo como un territorio simbólico de enigmas históricos en los cuales cada expresión corporal articula un paradigma entre su experiencia y el contexto. Este proyecto de investigación académica, analiza los efectos fenomenológicos que se generan en la danza cuando está mediada por sistemas de red. Para el efecto, la indago desde un enfoque interdisciplinario con el objetivo de detectar sus cualidades disciplinarias, sociales y tecnológicas en las cuales están presentes la situación cultural, el movimiento y las manifestaciones dancísticas; todas ellas en su respectivo contexto socio-histórico porque solo en él se perciben los ejercicios y/o prácticas escénicas y sociales. El estudio de caso consistió en una obra interdisciplinaria telemática de la que formé parte tanto, en los aspectos creativos, como administrativos y tecnológicos. Para este proyecto, ya en calidad de investigadora, mantendré las distancias y aproximaciones a la experiencia de caso según convenga al proceso de investigación.

\section{Palabras clave}

Danza en redes; cuerpo red; danza telemática; danza en espacios virtuales

\footnotetext{
Abstract

I perceive the human body as a symbolic territory of historical enigmas in which corporal expressions articulates paradigms between its experience and its context. This academic research project analyzes the phenomenological effects that are generated on dance when it is mediated by network systems. For this purpose, I approach it from an interdisciplinary perspective with the aim of detecting its disciplinary, social and technological qualities in which the cultural situation, the movement and the dance manifestations are present, all of them in their respective socio-historical context because only there it is perceived the performing and social practices. The study case consisted of a telematics interdisciplinary performance in which I was a part
}

of, from the creative, administrative and technological aspects. For this investigation, as a researcher, I will maintain the distances and approaches to the subject as suitable to the research process.

\section{Keywords}

Dance in networks; body network; telematic dance; dance in virtual spaces

\section{Resumo}

Entendo o corpo como um território simbólico de enigmas históricos em que cada expressão corporal articula um paradigma entre sua experiência e o contexto. Este projeto de pesquisa acadêmica analisa os efeitos fenomenológicos que são gerados na dança quando ela é mediada por sistemas de rede. Para tanto, investigo de uma perspectiva interdisciplinar com o objetivo de detectar suas qualidades disciplinares, sociais e tecnológicas em que a situação cultural, o movimento e as manifestações da dança estão presentes, todos em seu respectivo contexto sócio-histórico, porque só assim os exercícios ou práticas cênicas e sociais são percebidos. $\mathrm{O}$ estudo de caso consistiu em um trabalho interdisciplinar telemático do qual fiz parte, tanto no aspecto criativo, administrativo e tecnológico. Para este projeto, como pesquisador, manterei as distâncias e abordagens da experiência do caso conforme apropriado para o processo de pesquisa.

\section{Palavras-chaves}

Dance em redes; corpo rede; dança telemática; dança em espaços virtuais

El cuerpo, como complejidad cultural encarnada, constituye además un espacio ideológico de acción y de significación por el cual se develan procesos de subjetivación: sociales, artísticos, políticos y tecnológicos, por mencionar algunos. La relación que me propongo investigar, entre el cuerpo y su contexto, es aquella que se genera cuando está atravesado por redes de telecomunicación 
en y desde la escenificación de una danza; analizo la forma con la que se configura o reconfigura el cuerpo, su materialidad, los diversos modos de representación y la manera en que las redes de telecomunicación abren campos mentales, de acción, de propagación e intercambios humanos, que bien pueden apreciarse mientras la danza es ejecutada.

Desde un mundo mediado por sistemas de redes, el cuerpo y sus posibilidades de activación/movimiento, trascienden su propia contención orgánica; interactúa con varios límites que se extienden hacia fuera o hacia adentro de su piel misma. El campo de acción del cuerpo es aquel de su deseo y de sus posibilidades de visión, representación y transmisión; no se detiene solamente en aquellos aspectos que extienden los sentidos y los límites. El movimiento de un cuerpo revela la existencia del ser, nos deja ver la esencia con la que recorre el mundo, la manera en que define las tensiones individuales y colectivas. Hay una relación muy estrecha entre el cuerpo y la dimensión espacial y temporal en la que vive.

Su forma de moverse deja ver numerosos indicios de lo que le ocurre, la manera en que dialoga consigo mismo y con su entorno; el modo en que se conecta e interactúa con sus interlocutores. El movimiento corporal como lenguaje, pone en evidencia los criterios sociales y culturales en los que el cuerpo desarrolla desplazamientos; se configuran o reconfiguran mutuamente y se establecen nuevas subjetividades en las que están presentes lo individual, lo colectivo, lo social y lo global.

La danza puede tomar una enunciación muy amplia, puede ser desde un movimiento corporal espontáneo de gozo, hasta una serie de acciones formalizadas en códigos de composición disciplinar. Su noción se liga estrechamente a la idea de cuerpo colectivo, de identidad social, de representación y de narrativa. La manera en que la idea de cuerpo transita a lo largo de la historia, es revelador del contexto al cual pertenece. Las sociedades van marcando cambios en la dimensión de esa idea que se aprecian desde las esferas sociales, hasta las diversas manifestaciones culturales y artísticas. Por eso, lo que llamamos cuerpo se refiere a un territorio simbólico que encierra enigmas históricos en los cuales cada forma de expresión corporal implica un paradigma de acercamiento con la experiencia y con su contexto. La danza es la especialista del movimiento, son los vocablos con los que elabora sus discursos, con lo que analiza la vida, manifiesta y enuncia su realidad. En consecuencia, el cuerpo que baila deja ver cuantiosos testimonios y es un material excelente para elaborar lecturas y análisis.

En el año 2013, se realizó una obra escénica con tres bailarines, que construían su composición coreográfica de manera simultánea, desde tres países: México, Brasil y España. Interactuando en tres canales, por los cuales se estableció una conexión de ida y vuelta en alta definición; este evento fue visto, de manera presencial, en las tres ciudades como una obra dancística sui generis, ya que se reconfiguraban tres aspectos fundamentales del acto escénico: el espacio, la presencia y la representación. La obra también pudo observarse como una transmisión en vivo a través de Internet. El diálogo coreográfico se estableció entre el/la bailarín/a de cada país y la composición de imágenes proyectadas, en tamaño real, de los otros bailarines, para crear un juego de composición simultánea entre cuerpos orgánicos y cuerpos remotos; todo esto, en tiempo real. Paralelamente, una composición sonora se construía de manera conjunta con tres compositores, cada uno, desde su lugar de origen.

En México, este evento figura como el primer referente de puesta en escena de danza mediada por sistemas de tele-presencia. Se enlazaron de manera remota tres equipos de alta especialización en las artes y en las ciencias para trabajar, colaborativamente, una exploración 
que analiza el contexto artístico, tecnológico y científico desde una propuesta escénica.

Este suceso artístico es el eje articulador de mi investigación, particularmente, en los aspectos de experiencia de creación, producción e investigación basada en artes. El nombre de la obra referida es: EVD58' - Embodied in varios Darmstadt $58^{\prime} .^{3}$

EVD58', no solamente es interesante para los creadores y participantes del proyecto, o únicamente para la exploración e investigación en las artes; su relevancia la observo en relación con la sociedad contemporánea que nos contiene, en la manera en que nuestras percepciones se implican desde el pensamiento en redes, ideológica y operativamente. Su aporte lo encamino a pensar en una configuración global como en una reflexión temática e instrumental de nuestro ser contemporáneo. El arte imagina, propone y construye escenarios donde desarrolla ideas acerca de su realidad, con la intención de que fluyan entre sus asistentes y, probablemente, trasciendan hacia una especulación o cuestionamiento personal.

La conectividad de las redes no es un fenómeno que ahora nos asombre al igual que ocurría en 1982, cuando Roy Ascott organizaba la primera consulta planetaria del I Ching en Ars Electrónica; sin embargo, las interrogantes que se generan continuamente por los advenimientos tecnológicos ocurren con tal velocidad que es casi imposible mantener la pista del acontecer mundial. El arte y las ciencias se encargan de revisar, reflexionar e investigar la existencia en sus enigmas y problemáticas, incluso aquellos que todavía no lo advierten por la precipitación de su surgimiento, por ejemplo: ¿Qué pensamiento formula la danza desde una óptica epistemológica, ontológica e interdisciplinaria cuando extiende su lugar de acción y exploración más allá de los lugares de

Obra realizada con el apoyo de Iberescena y la Dirección de Danza de la UNAM (2013). escenificación, tales como, los que articulan los sistemas de comunicación de redes? o ¿Cómo, a partir del estudio de acontecimientos dancísticos que utilizan sistemas de red (tele-presencia e Internet), podemos observar cambios de paradigmas tanto en la práctica artística como en la sociedad? Estas, son dos de las preguntas que rigen la investigación como ejes centrales del cuerpo de investigación y que generan diálogos con otras más. El cuerpo de 2018 desea y relaciona diferentes circunstancias que el de 1982.

El espacio donde actualmente se desarrolla la danza es muy amplio, me enfoco en aquel que ocurre en el contexto de la mediación en las redes de comunicación, no solo como un canal mediático más sino como un dispositivo articulador y transformador de la experiencia performática. Los casos de danza seleccionados, para esta investigación, pretenden cubrir los aspectos significativos de la danza y la mediación en red, como materia y como medio. Diversos modos de realizar la danza y diversas formas de utilizar la tecnología telemática.

El método utilizado para llevar a cabo este proceso de indagación se conforma por dos vías reflexivas en las que baso mi hipótesis. El caso 1 de estudio, lo analizo desde una posición de creadora/investigadora, ya que tuve una participación central en la Obra EVD58' en la creación, planeación y producción. La otra vía de análisis es un cuerpo de 4 casos de danza de autoría diversa, en los que mi aproximación es desde un lugar de observadora/investigadora (ver tabla 1). Estos dos estudios de caso, establecen una estructura analítica en la que se forma un espacio de reflexión para dos posiciones encontradas de la danza. El afán es hacerlas dialogar en sus diferencias, en sus coincidencias y en sus contradicciones y extraer de los contrastes reflexiones que ayuden a ilustrar mejor los espacios de creación, difusión y distribución de la danza. 


\begin{tabular}{|ll|}
\hline Caso 1 & Caso 2 \\
\hline $\begin{array}{l}\text { Danza institucionalizada } \\
\text { (Internet2 - UCAID, University Corporation for } \\
\text { Advanced Internet Development) }\end{array}$ & Danza no Institucionalizada \\
\hline EVD58' & $\begin{array}{l}\text { a) Evolution of dance } \\
\text { b) Bruno Mars - 24 Magic } \\
\text { c) Original Amari y Yo bailando de } \\
\text { vueltas! } \\
\text { d) } 24 \text { Hours Happy }\end{array}$ \\
\hline
\end{tabular}

Tabla 1. Elaboración de la autora.

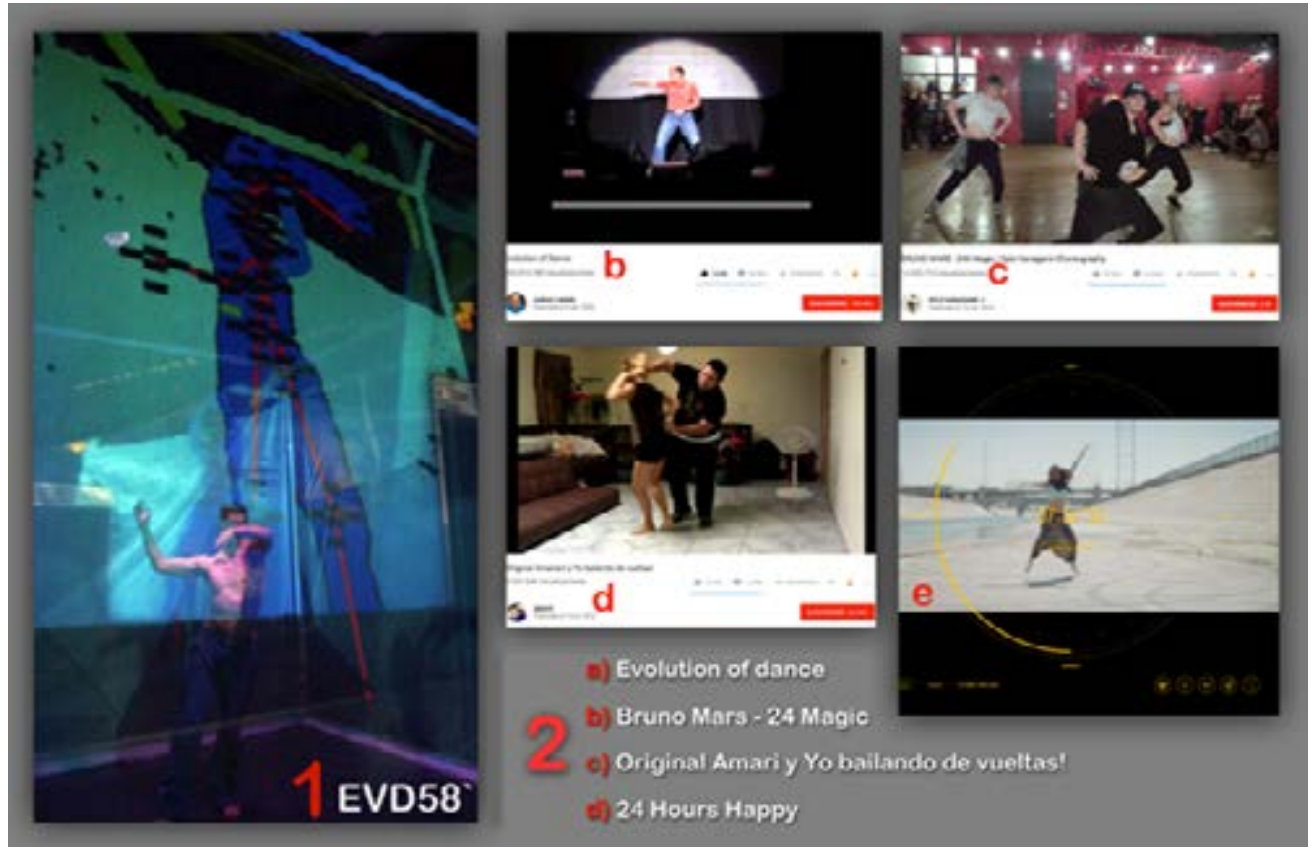

Imagen 2. Fotografías que ilustran los casos de estudio. Elaboración de la autora. 
Es fundamental la diferenciación que hago en la investigación entre la producción dancística que se realiza dentro de un entorno universitario, plantel académico, grupo de investigación o compañía profesional; todas ellas con suficientes recursos operativos, humanos, disciplinares y tecnológicos respecto de aquella producción que se realiza en espacios íntimos, domésticos, sociales, colectivos; pero, con recursos privados o de autogestión. Los nombro aludiendo a la maquinaria que los ensambla como institucionales y no institucionales. Evito la clasificación hacia el profesionalismo o la ejecución porque me interesa destacar con qué articuladores de producción cada grupo resuelve su realización.

En el caso 1, podemos observar un gran apoyo institucional, logístico, especializado. Fue un extenso equipo de trabajo de profesionales especialistas todos en su área e incluso enlazando, interinstitucionalmente, varios objetivos comunes de investigación (Danza UNAM, DGTIC, TVUNAM). Además de los enlaces con colegas internacionales en equivalencia de sectores con la Universidad Federal de Bahía, Brasil y con Konic Thtr y su gran equipo de científicos especialistas. En el caso 2, el grupo es seleccionado y definido como no institucional, que forman un cuerpo de análisis con una diversidad temática, algunas de producción "casera", otras con producción comercial "main stream", pero que el factor común en ellas es el soporte de existencia, todas surgidas y circulando libremente desde Internet comercial.

Cinco objetos artísticos develan cualidades más allá de las disciplinares, proponen una combinación de miradas disciplinares que ordenadas de manera transversal permiten elaborar un discurso combinado con varias vías analíticas, canales de posibilidades para una condición que atraviesa al cuerpo de todos nosotros actualmente.

El orden de las capas de análisis que se consideraron en la investigación no es jerárquico; la intención en todo caso, fue para componer un instrumento metodológico y una estrategia de estudio, por la cual aproximarme con la óptica conveniente para el momento de trabajo. Tanto de los estudios de performance, como de los new media, los estudios visuales y la sociología se problematizan los diversos momentos del argumento central de este trabajo.

En la danza, cuando se articula con recursos de red, estallan varios fenómenos escénicos que replantean nuevos paradigmas. Se trastocan los protocolos tradicionales de creación y de participación situando, tanto a creadores como a espectadores, en experiencias escénicas y estéticas de complejas estructuras narrativas.

\section{Conclusiones}

Tal vez, en los inicios de las exploraciones de arte y telemática prevalecía el tono descriptivo, ilustrativo, orientado a dimensionar el alcance que una nueva extensión espacio-temporal brindaría a nuestro entorno. En ese entonces, la condición telemática no era parte todavía de lo cotidiano, tampoco eran las herramientas habituales para construir y dar sentido del momento; poco a poco fueron saliendo de los confines de las instituciones y consorcios, aproximándose en acceso y en menor costo a la sociedad actual. Desde los años ochenta, Nam June Paik, en su manifiesto Art and Satellite cita a Henri Poincaré diciendo, "no estamos descubriendo cosas nuevas, más bien, nuevas formas de relacionarnos con las cosas ya existentes." (Paik, 1984). No son cosas nuevas, son nuevos pensamientos.

En estos momentos, la telemática es parte de nuestra realidad y continuamente estamos configurando y reconfigurando la manera de existir, de relacionarnos y de elegir criterios para definir conductas y comportamientos. Pero, como dice Barbero, la verdad cultural y nuestro mestizaje, no desde el sentido racial sino de las discontinuidades culturales que revuelven tanto lo indígena con lo rural, con lo urbano, lo popular y lo masivo (Barbero, 1991). A esta particularidad de América 
Latina hay que agregarle la confrontación con la intervención impetuosa de los entornos digitales, de las telecomunicaciones en una cercanía y uso crecientes también; México es el tercer país en el mundo en el uso de redes sociales (León, 2016).

Probablemente, la danza es entre el resto de las manifestaciones artísticas, la que sufre más contratiempos en su devenir investigación, manifestación y postura artística. No es inmune a los múltiples prejuicios con los que se amenaza su desarrollo; y, a esto se le agrega el factor de las condiciones necesarias para que se articulen todos sus valores de estructura artística, social y política. La libertad y las posibilidades de existencia no siempre se proporcionan para la creación, más bien, casi nunca surgen fácilmente; hay que procurarlas, hay que solicitarlas, hay que construirlas. El Internet comercial está siendo tomado por múltiples innovadores, los creadores no paran, pero es un océano de intereses algunos evidentes y otros no tanto; hay que lidiar con políticas diseñadas para otros intereses que no son los de la creación artística. Evidentemente, hay proyectos artísticos que triunfan en ese ambiente así sea hostil; pero, ¿qué sería si el medio es más apropiado?

En México la exploración de la danza, hacia nuevos lenguajes y vínculos tecnológicos, avanza intermitentemente; en el aspecto de la construcción con estructuras telemáticas, es todavía más discontinua $\mathrm{y}$, cuando llega a ocurrir, es probablemente desde un estado de exploración esencial. Esto, no significa una problemática o un pendiente irresuelto, lo que refleja es la falta de posibilidades para la exploración, la investigación y la búsqueda de significado. Lo que es grave, es la dificultad para dialogar con nuestra realidad, con las instituciones culturales y educativas para establecer espacios que apoyen intereses en estos temas. Somos seres telemáticos, con una nueva reconfiguración corporal y ese cuerpo todavía no se ve reflejado en su extensión, en la creación de la danza contemporánea en México.

El acceso a los espacios que posibiliten la exploración de la danza contemporánea y la telemática son muy escasos; estos requieren el uso de plataformas con especificaciones y mecanismos de interconexión, muy particulares. Irónicamente la infraestructura existente en las instituciones no es la limitante, lo que limita es la posibilidad de disponer de esos espacios.

Por otro lado, las comunidades virtuales no detendrán su expansión y crecimiento, hay muchas razones para que ese desarrollo vertiginoso siga, cada vez, con mayor progresión; hay conquistas tecnológicas, intereses políticos y, sobre todo, una industria de la comunicación muy productiva, económicamente hablando. La danza que se desarrolla en las comunidades en red es muy activa, constante y en continua creación y configuración de sus modos de interrelación. El cuerpo telemático de las comunidades en red es muy presente y muestra tanto la singularidad de propuestas individuales como la singularidad del cuerpo colectivo al cual pertenecen. La manera de relacionarse, de cuestionar, de reflexionar, de apropiarse de estructuras ya disponibles. Este acontecimiento dancístico ejemplifica lo mencionado anteriormente por Alsina, donde la innovación tecnológica, en una comunidad, es factor endógeno del proceso social.

\section{Referencias}

Barbero, J. (1991). De los medios a las mediaciones. Comunicación, cultura y hegemonía. México: G. Gili.

León, M. (27 de octubre, 2016). "México, el tercer país en el mundo en uso de redes sociales: Presidencia de la República". El Financiero.

Paik, N. (1984). Art \& Satellite. Berlín: DAAD Galerie. 